\title{
Carbon from the continents
}

\author{
Emissions of $\mathrm{CO}_{2}$ from the continents and underlying mantle are emerging as potentially important drivers of past \\ climate fluctuations.
}

$\mathrm{n}$ the face of human-induced climate change, Earth's carbon cycle has come under intense scrutiny. The cycling of carbon between shallow reservoirs - stores of fossil fuels, the atmosphere, oceans, soils and the biosphere - is a familiar concept. But, as discussed in a range of papers in this issue, the carbon cycle extends beyond these surface stocks deep into the Earth.

Unlike our neighbouring planet Venus, Earth has maintained for billions of years a temperature range that is hospitable to life, not least thanks to the slow cycling of carbon between the planet's interior and surface: carbon locked into the crust is transported into the Earth at subduction zones and released back to the surface via metamorphism and volcanism. The size of the deep carbon stocks is vast. The crust and mantle may contain 100,000 times that of the shallow carbon reservoirs ${ }^{1}$. But the natural emission of carbon from our planet's interior occurs slowly, for the most part giving Earth's systems a chance to adjust to and counter these emissions with natural sequestration.

Significant fluctuations in climate before humans had an influence may reflect periods when Earth's slow, deep carbon cycle was out of balance. Reconstructions of waxing and waning magma production over the past 720 million years had pointed to potential links between transitions to greenhouse states, continental breakup and dispersal, and periods of intense volcanic activity above subduction zones ${ }^{2}$.

When continents rift and split apart, as is happening in the East African Rift system today, a new ocean basin forms in the gap. The surface area required for the creation of oceanic lithosphere is usually compensated by the consumption of older oceanic lithosphere elsewhere on the planet, via subduction at tectonic plate boundaries. Sinking plates, in turn, release fluid and volatiles, including carbon, that trigger volcanism at the surface. In this way, subduction zone volcanoes, similar to those found in the Cascades and Andes mountain ranges today, could be the source of high $\mathrm{CO}_{2}$ emissions that led to past greenhouse conditions ${ }^{2}$.

However, it now seems that carbon emissions from continental plate interiors,

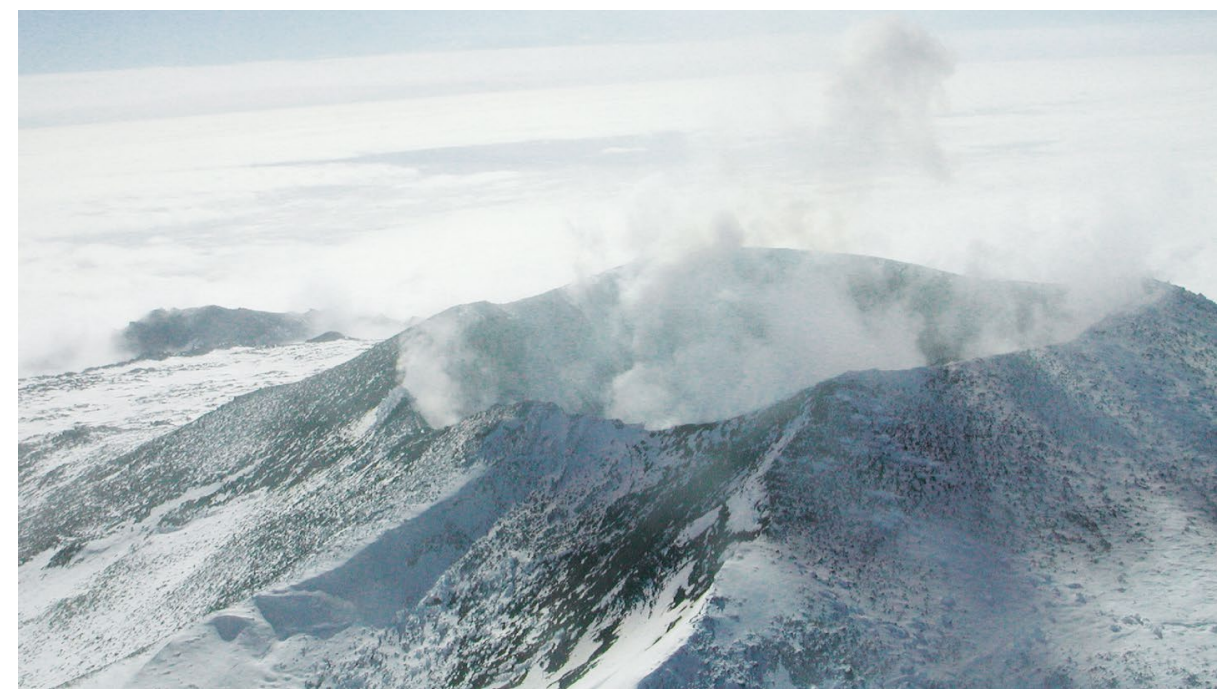

Credit: Tim Paulsen

rather than subduction zone plate boundaries, could also be drivers of past climate fluctuations. Trace element analyses show that many minerals created by a pulse of volcanism about 580 million years ago, during the warm Ediacaran period, were sourced from carbonatite volcanoes. These are a specific type of volcano that, as the name suggests, are carbon rich and release large volumes of mantle-derived $\mathrm{CO}_{2}$ during eruptions (p930; N\&V p884). These unusual volcanoes are typically found in continental rift zones, not subduction zones, implying that the warm Ediacaran climate could ultimately have resulted from a pulse of $\mathrm{CO}_{2}$ from the mantle.

Further support for a link between continental rifting and past climate change comes from work by Brune and colleagues (p941; Sketch-Up p886) in which plate tectonic reconstructions and carbon cycle modelling show that periods with elevated palaeo-atmospheric $\mathrm{CO}_{2}$ concentrations coincided with episodes of extensive continental rifting; particularly between about 160 and 100 million years ago, as Pangaea and Gondwana broke apart to form the Atlantic Ocean. During these times, the continental rift systems were far longer than at present and could have released more than three times as much $\mathrm{CO}_{2}$ as rift systems emit today.

Such an important role for continental rifts in the deep carbon cycle makes sense.
Measurements of diffuse emissions through the crust and along faults - in just a small section of the East African Rift are astonishingly high ${ }^{3}$. Foley and Fischer explore the possible causes for such high carbon contents in a Perspective on page 891 . They argue that carbon is added to and concentrated within continents from below, via mantle convection and mantle plume activity. At times in the past when the abundance of rifts on Earth was greater than today, continental breakup could have released up to $170 \mathrm{Mt}$ of carbon per year. Although orders of magnitude lower than human emissions, this is still a sufficient amount of carbon to significantly alter climate on geologic timescales.

If we wish to understand the influence the deep carbon cycle on past climate upheavals, we may need to pay more attention to carbon storage and release from continental crust, rather than focussing mostly on subduction zones.

Published online: 1 December 2017 https://doi.org/10.1038/s41561-017-0030-3

\footnotetext{
References

1. DePaolo, D. MRS Energy Sustain. https://doi.org/10.1557/ mre.2015.10 (2015).

2. McKenzie, N. R. et al. Science 352, 444-447 (2016).

3. Lee, H. et al. Nat. Geosci. 9, 145-149 (2016).
} 